\title{
A cost-of-illness study of spina bifida in Italy
}

This article was published in the following Dove Press journal:

ClinicoEconomics and Outcomes Research

I July 2013

Number of times this article has been viewed

Giorgio L Colombo ${ }^{1,2}$

Sergio Di Matteo²

Marta Vinci ${ }^{3}$

Claudia Gatti ${ }^{4}$

Maria Paola Pascali ${ }^{5}$

Mario De Gennaro ${ }^{6}$

Elena Macrellino ${ }^{7}$

Giovanni Mosiello ${ }^{5}$

Tiziana Redaelli ${ }^{7}$

Francesca Schioppa ${ }^{7}$

Cristina Dieci ${ }^{8}$

'University of Pavia, Department

of Drug Sciences, School of Pharmacy,

Pavia, Italy; ${ }^{2}$ S.A.V.E. Studi Analisi Valutazioni

Economiche, Milan, Italy; ${ }^{3}$ Associazione

Walter Vinci Onlus, Milan, Italy; ${ }^{4}$ Centro

Spina Bifida, Azienda Ospedaliera di Parma,

Parma, Italy; ${ }^{5}$ Centro Spina Bifida, Ospedale

Pediatrico Bambino Gesù, Rome, Italy;

${ }^{6}$ Ospedale Pediatrico Bambino Gesù, O.C.

di Urodinamica, Rome, Italy; ${ }^{7}$ Centro Spina

Bifida, Ospedale Niguarda Milan, Italy; ${ }^{8}$ ASB

Associazione Spina Bifida Italia, Piacenza, Italy

\section{Video abstract}

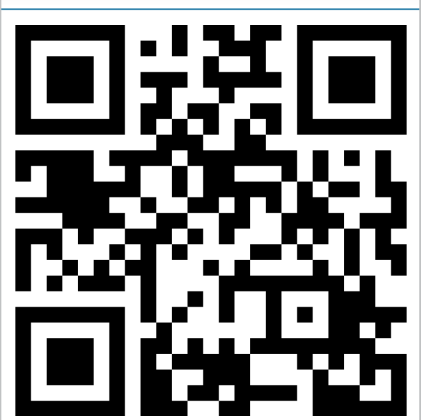

Point your SmartPhone at the code above. If you have a QR code reader the video abstract will appear. Or use: http://dvpr.es/IONioij

Correspondence: Giorgio L Colombo S.A.V.E. Studi Analisi Valutazioni Economiche, Via Previati,

74 - 20149 Milan, Italy

Tel +3902485 I 9230

Fax +3902 73960369

Email giorgio.colombo@savestudi.it
Introduction: Spina bifida (SB) is a congenital malformation of the spinal cord, nerves, and adjacent covering structures, with different levels of severity and functional disability. The economic cost of spina bifida and its prevention using folic acid have never been estimated in Italy. This study was conducted to define the cost of illness of SB in Italy.

Methods: A retrospective multicenter observational study on the social cost of patients with SB was carried out in three SB centers in Italy. Cost data were collected relating to the 12 months preceding the enrollment time (T0), and subsequently 3 months after the T0 time ( \pm 20 days) through a case report form designed to collect the relevant information on the costs incurred during the period considered. The data for all patients were analyzed through multivariate analysis on the main parameters.

Results: We enrolled 128 patients equally divided between males and females, with a mean age of 13 years (minimum, 0; maximum, 29). Diagnosis was mostly postnatal, with 64 cases diagnosed at birth and 33 cases diagnosed subsequently. The lesion severity levels, as defined in the inclusion criteria, were walking (52 patients); walking with simple orthoses (33 patients); walking with complex orthoses (16 patients); and nonwalking, (25 patients). The anatomic type identified is open SB in most cases ( 84 patients), followed by closed SB (37 patients) and SB occulta ( 3 patients). The most significant cost per year was for assistive devices, for a total of $4307.00 €$, followed by hospitalization (907.00€), examinations (592.00 $€$ ), and drug therapy ( $328.00 €$ ). Cost breakdown by age range shows that the highest costs are incurred in the $0-4$ age range. The highest cost was for cases of open SB $(12,103.00 €)$. The cost/degree of severity ratio showed that the highest cost was for nonwalking patients $(14,323.00 €)$, followed by patients walking with complex orthoses $(13,799.00 €)$.

Conclusion: The data from this study show that the mean total cost for a patient with SB was $11,351.00 €$ per year. Based on data provided by the Italian Institute of Health, we can estimate a total annual social cost of about 60 million Euros per year for SB in Italy. Cost of illness was correlated with age and degree of severity of SB.

Keywords: spina bifida, cost of illness, pharmacoeconomics, cost analysis

\section{Introduction}

Spina bifida (SB) is a congenital malformation of the spinal cord, nerves, and adjacent covering structures (vertebrae, muscles, and skin) with different levels of severity and functional disability. However, in typical cases, the disorder is characterized by a spinal cord lesion (usually myelomeningocele with a thoracic, lumbar, or lumbosacral location) with consequent paralysis of the lower limbs, hydrocephalus, fecal and urinary incontinence, and reduced sensitivity. ${ }^{1,2}$ The malformation presents during the first month of pregnancy and can be recognized at birth - although prenatal diagnosis is often possible - in the evident and open form, whereas diagnosis can be 
more difficult for SB occulta and related forms; more than $90 \%$ of neural tube defect cases are prenatally diagnosed at a median gestation of 17 weeks. ${ }^{1,3}$ It is often associated with other malformations, such as hydrocephalus and Chiari malformations. In Italy, SB has an incidence of four to six cases per 10,000 pregnancies (about 360 new cases a year); in Great Britain it is eight out of 1000, and one out of 1000 in Japan. ${ }^{1,4,5}$ The estimated frequency of SB in terms of total prevalence (number of cases of SB at birth + number of cases of SB in therapeutic termination of pregnancy after prenatal diagnosis), and in terms of birth prevalence (number of cases of SB amongst live births), can be obtained from the malformation registers kept by some Italian regions. ${ }^{6}$ It is estimated that the current total prevalence of SB in Italy is 0.38 per 1000 live births. If we consider an approximately $70 \%$ therapeutic termination of pregnancy rate, the birth prevalence is 0.11 per 1000 (one of every 8750 births, about 64 cases/year). However, no estimates have been published of the population prevalence (the number of people with SB outcomes present in the population). In the absence of a specific and expensive survey, it could be approximated on the basis of the birth prevalence rates for past years and of the estimated survival. ${ }^{7,8}$

The economic cost of SB (and of neural tube defects in general) and its prevention using folic acid have never been estimated in Italy. Evaluation is also lacking in other European countries and in North America. ${ }^{9-12}$ However, this evaluation is of great importance, as it would allow an assessment of the cost-benefit ratio of current folic acid supplementation and the cost-benefit ratio of dietary fortification. $^{12,13}$

In public health care, the importance of health problems is expressed in terms of frequency (incidence and prevalence), severity (mortality), and total costs. Studies on the social costs of a disease are useful for quantifying the absorption of resources caused by a given illness over a certain period of time. Any illness entails negative effects on the living conditions of the patients and their families, and therefore on society. ${ }^{14-16}$ The analysis of the total (direct and indirect) costs of a certain illness in a given population is called the cost of illness (COI) calculation. Studies on the COI aim at quantifying the cost of an illness or clinical event, and consequently they do not include comparisons with alternatives. ${ }^{17}$ The social cost of an illness (ie, the economic burden and level of lost productivity for society) refers to three main components: direct costs (the resources used for the prevention and treatment of the illness and associated diseases), indirect costs (attributable to loss of production due to the absence of affected subjects from work), and intangible costs (psychosocial costs, such as the suffering and discomfort caused by the disease). ${ }^{18}$

COI analysis is based on epidemiological data (Figure 1). By estimating the number of individuals suffering from the illness in question, it is possible to determine the mean annual cost per individual and the total annual cost of resources consumed by the patients. Depending on the epidemiological criteria employed, COI studies can be developed using two approaches. The first, prevalencebased approach, estimates the overall cost of an illness in a given population, over a given period. The second, incidence-based approach, evaluates expenditure for the lifetime cost of the cases diagnosed in a certain year. The most commonly used COI analysis methods can be divided into: top-down and bottom-up. The top-down method refers to aggregate data available on a nationwide level and involves the attribution of total health care expenditure to individual illnesses. ${ }^{17,19}$ The bottom-up method refers to the direct consumption of resources, based on epidemiological data, and the cost of the individual factors, resulting in cost calculation as the product of mean resource consumption and relative price/cost. COI studies can therefore support health care policies and provide guidance for health care decision making through the following actions: identifying the different cost components for the diagnosis and treatment of a specific illness, and to what extent they are a burden on society; information and educational function; guiding research towards prevention activities; identifying clinical priorities with an important economic impact in the fight against the disease; identifying patients' consumption behavior and evaluating and comparing physicians' prescription behaviors; and identifying the elements that are indispensable for performing subsequent economic evaluation studies (cost-effectiveness, cost-benefit analysis, and

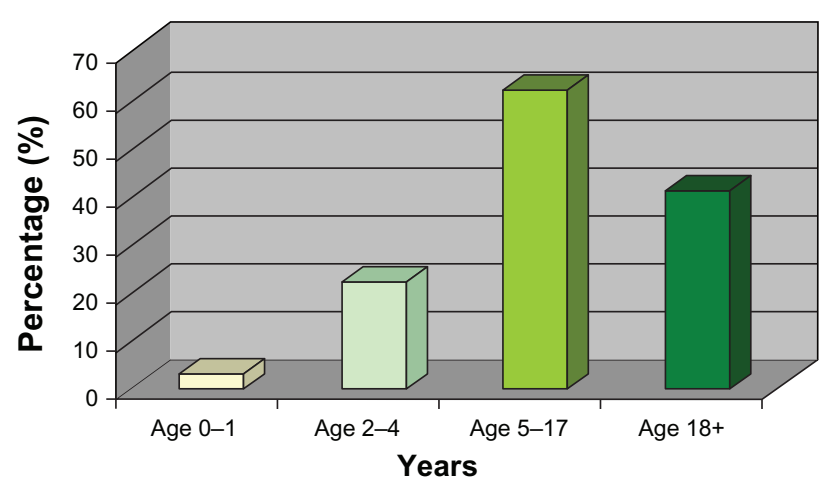

Figure I Patients' distribution by age. 
so on). ${ }^{19}$ This study was carried out to define the different types of costs associated with the diagnosis and treatment of SB patients: direct health care costs; direct nonhealth care costs (transportation, assistance costs, and so on) sustained by the patients, their families, public facilities, and so on; and indirect costs (value of work days lost by the patients and their families).

\section{Patients and methods}

The primary objective of this study was to analyze the social and medical impact of the management of patients with SB and, specifically, to evaluate direct costs (surgery, hospital stays, rehabilitation and tertiary prevention initiatives, financial benefits for the consequent disability) and indirect costs (eg, parents' loss of productivity for caregiving, loss of productivity of the affected subject) associated with SB. The secondary objective was to collect data on the various cost components burdening the National Health Service (NHS; Servizio Sanitario Nazionale) and society for the management of this type of patient, and to estimate the annual cost to society for the treatment of SB.

This retrospective multicenter observational study on the social cost of patients with SB was carried out in three SB centers in Italy (Niguarda in Milan, Ospedale Maggiore in Parma, and Bambino Gesù Children's Hospital in Rome)

Table I Social and demographic characteristics of the patients

\begin{tabular}{|c|c|c|c|}
\hline & Count & Percent & Graph of percent \\
\hline \multicolumn{4}{|l|}{ Center } \\
\hline Parma & 60 & 46.88 & |||||||||||||||||| \\
\hline Milan & 48 & 37.50 & |||||||||||||| \\
\hline Rome & 20 & 15.63 & $\|||||$ \\
\hline \multicolumn{4}{|l|}{ Age } \\
\hline Mean and SD & 13.27 & 8.31 & \\
\hline \multicolumn{4}{|l|}{ Sex } \\
\hline Female & 63 & 50.00 & |||||||||||||||||||| \\
\hline Male & 63 & 50.00 & |||||||||||||||||||| \\
\hline \multicolumn{4}{|l|}{ Schooling } \\
\hline Nursery school & 7 & 8.14 & \|\| \\
\hline Elementary school & 24 & 27.91 & |||||||||| $\mid$ \\
\hline Junior high school & 22 & 25.58 & ||||||||| \\
\hline High school & 23 & 26.74 & |||||||| $\mid$ \\
\hline $\begin{array}{l}\text { University, } \\
\text { specialization }\end{array}$ & 10 & 11.63 & ||I| \\
\hline \multicolumn{4}{|c|}{ Employment status } \\
\hline Employed & 59 & 64.84 & |||||||||||||||||||||||||| \\
\hline Housewife & 21 & 23.08 & |||||||| \\
\hline Unemployed/ & 9 & 9.89 & ||| \\
\hline \multicolumn{4}{|l|}{ looking for a job } \\
\hline Retiree & 2 & 2.20 & | \\
\hline Full-time & 39 & 62.90 & |||||||||||||||||||||||||| \\
\hline Part-time & 23 & 37.10 & |||||||||||| $\mid$ \\
\hline
\end{tabular}

Abbreviation: SD, standard deviation. between February 2008 and April 2008, with follow-up at 3 months. During the study, cost data were collected relating to the 12 months preceding the enrollment time (T0), and subsequently at $\mathrm{T} 3$ ( 3 months after the $\mathrm{T} 0$ visit \pm 20 days) by reading a report form over the telephone provided at $\mathrm{T} 0$ and used by the patient to collect the relevant information on the costs incurred during the period considered. The study included all consecutive patients with SB presenting to the centers involved during the enrollment period and who gave

Table 2 Clinical profile of the enrolled patients

\begin{tabular}{|c|c|c|c|}
\hline $\begin{array}{l}\text { Spina bifida } \\
\text { diagnosis }\end{array}$ & Count & Percent & $\begin{array}{l}\text { Graph } \\
\text { of percent }\end{array}$ \\
\hline \multicolumn{4}{|l|}{ Before birth } \\
\hline$\leq 25$ th week & 12 & 35.29 & |||||||||||| $\mid$ \\
\hline$>25$ th week & 9 & 26.47 & $|\||||||||$ \\
\hline Yes & 7 & 20.59 & |||||||| \\
\hline Anatomical scan & 6 & 17.65 & |||||| \\
\hline \multicolumn{4}{|l|}{ Gestational age } \\
\hline$>25$ th week & 26 & 50.98 & ||||||||||||||||||||| \\
\hline$\leq 25$ th week & 25 & 49.02 & |||||||||||||||||||| \\
\hline \multicolumn{4}{|l|}{ After birth } \\
\hline Birth & 64 & 65.98 & ||||||||||||||||||||||||||| \\
\hline Subsequent days & 33 & 34.02 & |||||||||||||| \\
\hline \multicolumn{4}{|l|}{ Days after birth } \\
\hline Mean and SD & 204.14 & 508.22 & \\
\hline \multicolumn{4}{|l|}{ Walking } \\
\hline Walking & 52 & 41.27 & |||||||||||||||| \\
\hline $\begin{array}{l}\text { Walking with } \\
\text { simple orthoses }\end{array}$ & 33 & 26.19 & $|\||||||||$ \\
\hline Nonwalking & 25 & 19.84 & |||||| \\
\hline \multicolumn{4}{|l|}{ complex ortheses } \\
\hline \multicolumn{4}{|c|}{ Anatomical type } \\
\hline Open SB & 84 & 67.74 & |||||||||||||||||||||||||||| $\mid$ \\
\hline Closed SB & 37 & 29.84 & |||||||||||| \\
\hline SB occulta & 3 & 2.42 & l \\
\hline \multicolumn{4}{|c|}{ If closed SB: associated malformation } \\
\hline Urinary & 9 & 40.91 & |||||||||||||| $\mid$ \\
\hline Anorectal & 6 & 27.27 & ||||||||| \\
\hline Cardiopathy & 3 & 13.64 & \|\|$\|$ \\
\hline \multicolumn{4}{|l|}{ and urinary } \\
\hline $\begin{array}{l}\text { Anorectal } \\
\text { and cardiopathy }\end{array}$ & I & 4.55 & । \\
\hline \multicolumn{4}{|l|}{ and urinary } \\
\hline \multicolumn{4}{|c|}{ Neurosurgery in the first year } \\
\hline Yes & 86 & 83.5 & |||||||||||||||||||||||||||||||||| \\
\hline No & 17 & 16.50 & |||||| \\
\hline \multicolumn{4}{|l|}{ Defect closure } \\
\hline Yes & 86 & 67.19 & |||||||||||||||||||||||||| $\mid$ \\
\hline No & 42 & 32.81 & ||||||||||||| \\
\hline \multicolumn{4}{|l|}{ VPS positioning } \\
\hline No & 69 & 53.91 & |||||||||||||||||||| $\mid$ \\
\hline Yes & 59 & 46.09 & |||||||||||||||||| \\
\hline
\end{tabular}

Abbreviations: SD, standard deviation; SB, spina bifida; VPS, ventriculoperitoneal shunt. 
their written informed consent to participate in the study, for a total of 128 evaluable patients at present.

\section{Inclusion and exclusion criteria}

The inclusion criteria were:

- walking motor deficit, walking with simple orthoses, walking with complex orthoses, nonwalking; and

- understanding of the aims of the study, able to respond and sign the informed consent form (the form was signed by parents if subjects were under 18 years of age.)

The exclusion criteria were:

- patients with dorsal level lesion up to D5/D6

- patients with open SB with significant comorbidity

- patients who are not reliable in the completion of the questionnaires

- patients participating in a clinical study when they reported to the center.

\section{Case report form (CRF)}

The patient questionnaire (CRF) attempted to reconstruct the diagnostic and therapeutic program of the enrolled patient and its costs to society and the NHS from T0 (enrollment) in the previous 12 months, if possible, and in the 3 months following enrollment. When appropriate, the information in the questionnaire was integrated with data from medical records and hospital discharge sheets. The CRF was provided to the Centers in Microsoft Excel (Microsoft Corporation, Redmond, WA, USA) format in order to guarantee rapid completion by the investigator and simultaneous checking by the monitor for any errors or missing data. Information at T0 was collected from the patient or parent by the investigator at the center. At the same time, patients were given a report form for the 3 months following $\mathrm{T} 0$ to be read by the patient or parent during the follow-up telephone call after 3 months.

\section{Cost analysis}

The treatments provided were recorded in the cost section. The questionnaire collected data for each patient and was divided into: characteristics of the patient; services provided (general practitioner examinations, specialist examinations, drug treatments, diagnostic examinations, laboratory tests, hospitalizations); and costs for nonmedical resources consumed due to treatment, such as, for instance, transportation of the patient and/or family to the hospital or outpatient examinations. The economic evaluation was performed in terms of the Italian society, the NHS, and the patient. Direct health care costs (drugs, hospitalization days, diagnostic tests) were quantified by multiplying the single item by the relative unitary cost. ${ }^{20}$ The costs for hospitalization were evaluated on the basis of the national Diagnosis-Related Group system available from the Italian Ministry of Health. ${ }^{21}$ Specialist medical examinations, laboratory tests, diagnostic procedures, and phototherapy sessions were based on the "2010 National Healthcare Range of Fees." 22 To assess the costs of prescribed pharmacological therapies, units of consumed resources were multiplied by the prices reported in the official Italian price list, taking into consideration the dosage and duration of the treatment. ${ }^{23}$ Health care services provided by the private sector and other private costs were evaluated based on the actual expenses incurred by the patients. Nonhealth care costs related to: (1) patients' or relatives' transportation; (2) home assistance by volunteers or relatives; (3) home assistance by others; and (4) home nursing assistance by others. These costs were evaluated based on the actual expenses incurred by the patients.

The human capital approach was used to estimate the productivity loss due to SB. ${ }^{20,24}$ Travel costs were not collected. Indirect costs included the value of lost production and loss of leisure time for nonemployees during the time of the study. Patients' time off work (lost working days, permanent reduction, or loss of work activities) was measured in terms of salary evaluation, with the assumption that income reflects productivity. The monetary value of 1 lost working day for patients was calculated as $98.44 €$, equal to the gross domestic product per capita/day. ${ }^{25}$ National income data were subsequently updated to 2011 according to official inflation rates and represented a mean value for all of Italy. The analysis was carried out from the society and NHS perspectives.

Table 3 Direct and indirect costs of spina bifida per year

\begin{tabular}{lll}
\hline & \multicolumn{2}{l}{ Cost per year } \\
\cline { 2 - 3 } & Euro/year & $\%$ \\
\hline Medical examinations & $€ 592$ & $5.2 \%$ \\
Emergency room & $€ 21$ & $0.2 \%$ \\
Hospitalizations & $€ 907$ & $8.0 \%$ \\
Diagnostic and laboratory tests & $€ 325$ & $2.9 \%$ \\
Drug treatments & $€ 328$ & $2.9 \%$ \\
Other treatments & $€ 62$ & $0.5 \%$ \\
Assistive devices & $€ 4,307$ & $37.9 \%$ \\
Direct health care & $€ 6,542$ & $57.6 \%$ \\
Transportation & $€ 165$ & $1.5 \%$ \\
Overnight stay & $€ 130$ & $1.1 \%$ \\
Travel and accommodation costs & $€ 295$ & $2.6 \%$ \\
Absence from work & $€ 4,514$ & $39.8 \%$ \\
(including accompanying persons) & & \\
Total & $€ 11,35 \mathrm{I}$ & $100.0 \%$ \\
\hline
\end{tabular}


All costs are expressed in Euros and were updated to 2011 values according to official inflation rates. ${ }^{26}$

\section{Statistical analysis}

The data for all patients were analyzed through multivariate analysis on the main parameters. The main investigated variables were:

- the patients' demographic characteristics

- stratification by age range

- any concomitant illnesses

- types of treatment (pharmacological, surgical, rehabilitation, and so on)

- methods for treating side effects and diagnostic procedures.

The is an observational (ie, nonexperimental study), in which the condition studied is observed over time. It is therefore a noninterventional epidemiological study that allows nature to take its course. Statistical analysis was conducted using the Statistical Package for the Social Sciences statistical software (SPSS Statistics version 14.0; IBM Corporation, Armonk, NY, USA). Descriptive statistics on study variables used traditional numerical synthesis measurements: mean, standard deviation, median, maximum and minimum value for the continuous variables, and frequency distributions for the categorical variables. Analysis of variance was used to compare the means of the quantitative variables between patient groups, stratified both by age ( 0 to 12 months; 1 to 4 years; 5 to 10 years; 11 to 14 years; 15 to 17 years; 18 to 30 years; 31 to 40 years; and over 40 years) and severity of illness. The statistical significance of any differences in the frequency distributions was tested using Pearson's Chi-square test. A value of $P<0.05$ was considered statistically significant.

\section{Results}

\section{Social and demographic characteristics}

We received 130 report forms, 128 of which were fit for analysis, and distributed between the participating centers as follows: Rome $(\mathrm{n}=20)$, Milan Niguarda $(\mathrm{n}=48)$, and Parma $(\mathrm{n}=60)$. The data relating to the social and demographic characteristics of the patients are summarized in Table 1 and Figure 1 . The patients' mean age was 13 years (minimum, 0 years; maximum, 29 years), equally divided between males and females. The majority of patients were in the school age bracket: 22 in the preschool range and 62 in the 6-17-year range, with a more or less even distribution between primary, junior, and high school. Most parents/caregivers who answered the questions about employment have jobs outside the home, most of which are full-time.

\section{Clinical profile}

As far as the clinical profile is concerned, in most cases diagnosis was postnatal, with 64 cases diagnosed at birth and 33 diagnosed subsequently. A total of 51 cases were diagnosed in the prenatal period, of which six were identified during the fetal morphology ultrasound scan. The lesion severity levels, as defined in the inclusion criteria, were: 52 walking patients; 33 walking with simple orthoses; 16 walking with complex orthoses; and 25 nonwalking. The anatomic type identified is open SB

Table 4 Degree of severity of spina bifida: direct and indirect costs per year

\begin{tabular}{|c|c|c|c|c|c|c|c|c|}
\hline & \multicolumn{2}{|c|}{$\begin{array}{l}\text { Walk with complex } \\
\text { orthoses }\end{array}$} & \multicolumn{2}{|l|}{ Nonwalking } & \multicolumn{2}{|c|}{$\begin{array}{l}\text { Walk with simple } \\
\text { orthoses }\end{array}$} & \multicolumn{2}{|l|}{ Walking } \\
\hline & Euros/year & $\%$ & Euros/year & $\%$ & Euros/year & $\%$ & Euros/year & $\%$ \\
\hline Medical examinations & $€ 644$ & $4.7 \%$ & $€ 791$ & $5.5 \%$ & $€ 650$ & $6.0 \%$ & $€ 403$ & $4.5 \%$ \\
\hline Emergency room & $€ 15$ & $0.1 \%$ & $€ 12$ & $0.1 \%$ & $€ 31$ & $0.3 \%$ & $€ 16$ & $0.2 \%$ \\
\hline Hospitalizations & $€ 0$ & $0.0 \%$ & $€ 1522$ & $10.6 \%$ & $€ 617$ & $5.7 \%$ & $€ 758$ & $8.4 \%$ \\
\hline Diagnostic and laboratory tests & $€ 82$ & $0.6 \%$ & $€ 480$ & $3.4 \%$ & $€ 333$ & $3.1 \%$ & $€ 292$ & $3.2 \%$ \\
\hline Drug treatments & $€ 614$ & $4.4 \%$ & $€ 450$ & $3.1 \%$ & $€ 229$ & $2.1 \%$ & $€ 263$ & $2.9 \%$ \\
\hline Other treatments & $€|3|$ & $0.9 \%$ & $€ 75$ & $0.5 \%$ & $€ 61$ & $0.6 \%$ & $€ 34$ & $0.4 \%$ \\
\hline Assistive devices & $€ 8158$ & $59.1 \%$ & $€ 4889$ & $34.1 \%$ & $€ 4419$ & $40.6 \%$ & $€ 2827$ & $31.5 \%$ \\
\hline Direct health care & $€ 9645$ & $69.9 \%$ & $€ 8219$ & $57.4 \%$ & $€ 6341$ & $58.3 \%$ & $€ 4593$ & $51.1 \%$ \\
\hline Transportation & $€ 165$ & $1.2 \%$ & $€ 165$ & $1.2 \%$ & $€ 165$ & $1.5 \%$ & $€ 165$ & $1.8 \%$ \\
\hline Overnight stay & $€ 130$ & $0.9 \%$ & $€ 130$ & $0.9 \%$ & $€ 130$ & $1.2 \%$ & $€ 130$ & $1.4 \%$ \\
\hline Travel and accommodation costs & $€ 295$ & $2.1 \%$ & $€ 295$ & $2.1 \%$ & $€ 295$ & $2.7 \%$ & $€ 295$ & $3.3 \%$ \\
\hline $\begin{array}{l}\text { Absence from work } \\
\text { (including accompanying persons) }\end{array}$ & $€ 3859$ & $28.0 \%$ & $€ 5809$ & $40.6 \%$ & $€ 4243$ & $39.0 \%$ & $€ 4100$ & $45.6 \%$ \\
\hline Total & $€ 13,799$ & $100.0 \%$ & $€ 14,323$ & $100.0 \%$ & $€ 10,878$ & $100.0 \%$ & $€ 8987$ & $100.0 \%$ \\
\hline
\end{tabular}




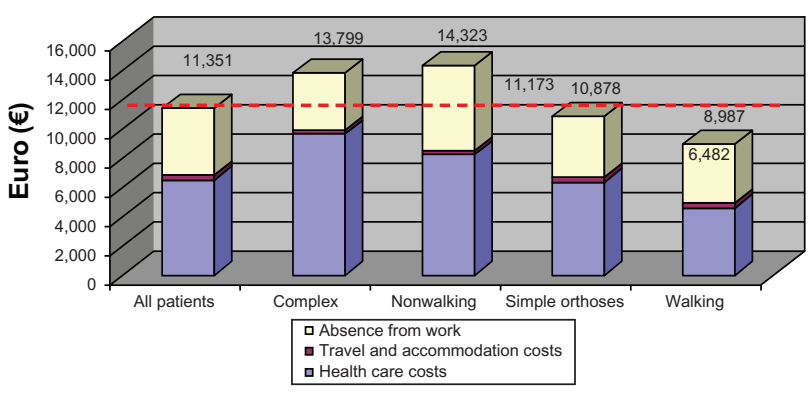

Figure 2 Degree of severity of spina bifida: direct and indirect costs per year.

in most cases $(n=84)$, followed by closed SB $(n=37)$, and SB occulta $(n=3)$. In the case of closed SB, the most commonly identified malformation is urinary, followed by anorectal. In all, 87 patients $(68 \%)$ in the analyzed sample had neurosurgery during the first year of life, almost always to close the defect by ventriculoperitoneal shunt implantation. Table 2 summarizes the data concerning the patients' clinical profile.

\section{Cost analysis}

Table 3 shows the direct and indirect costs incurred in by the families of the patients participating in the study, divided into medical examinations, hospitalizations, tests and procedures, pharmacological therapy, assistive devices, and the disease impact on work/study. As shown in Table 3, the mean COI per year per patient was $11,351.00 €$; the most significant

Table 5 Anatomical type ratio of spina bifida: direct and indirect costs per year

\begin{tabular}{|c|c|c|c|c|}
\hline & \multicolumn{2}{|l|}{ Open SB } & \multicolumn{2}{|l|}{ Closed SB } \\
\hline & Euros/year & $\%$ & Euros/year & $\%$ \\
\hline Medical examinations & $€ 625$ & $5.2 \%$ & $€ 54 I$ & $5.0 \%$ \\
\hline Emergency room & $€ 20$ & $0.2 \%$ & $€ 24$ & $0.2 \%$ \\
\hline Hospitalizations & $€ 554$ & $4.6 \%$ & $€ 1717$ & $15.8 \%$ \\
\hline $\begin{array}{l}\text { Diagnostic and } \\
\text { laboratory tests }\end{array}$ & $€ 385$ & $3.2 \%$ & $€ 206$ & $1.9 \%$ \\
\hline Drug treatments & $€ 403$ & $3.3 \%$ & $€ 177$ & $1.6 \%$ \\
\hline Other treatments & $€ 69$ & $0.6 \%$ & $€ 49$ & $0.5 \%$ \\
\hline Assistive devices & $€ 4985$ & $41.2 \%$ & $€ 2987$ & $27.5 \%$ \\
\hline Direct health care & $€ 704$ I & $58.2 \%$ & $€ 5701$ & $52.4 \%$ \\
\hline Transportation & $€ 165$ & $1.4 \%$ & $€ 165$ & $1.5 \%$ \\
\hline Overnight stay & $€ 130$ & $1.1 \%$ & $€ 130$ & $1.2 \%$ \\
\hline $\begin{array}{l}\text { Travel and } \\
\text { accommodation costs }\end{array}$ & $€ 295$ & $2.4 \%$ & $€ 295$ & $2.7 \%$ \\
\hline $\begin{array}{l}\text { Absence from work } \\
\text { (including accompanying } \\
\text { persons) }\end{array}$ & $€ 4767$ & $33.3 \%$ & $€ 4009$ & $36.9 \%$ \\
\hline Total & $€ 12,103$ & $100.0 \%$ & $€ 10,005$ & $92.0 \%$ \\
\hline
\end{tabular}

Abbreviation: SB, spina bifida. costs was for assistive devices, for a total of $4307.00 €$, followed by hospitalizations $907.00 €$, examinations $592.00 €$, and drugs $328.00 €$. Transportation costs amount to $165 €$, whereas the cost for the absence from work of the main caregiver was very significant, at $4514.00 €$. The cost breakdown by age range shows the highest costs were incurred in the $0-1$-year range, while they drop in the subsequent ranges and stabilize at approximately $9000.00 €$ when the patient reaches adulthood.

The cost-degree of severity analysis showed that the highest expenditure was for nonwalking patients $(14,323.00 €)$ and for patients walking with complex orthoses $(13,799.00 €)$; the highest cost component in this case is for assistive devices and medical examinations (Table 4 and Figure 2). As indicated in Table 5 and Figure 3, as far as the cost-anatomical type ratio is concerned, the highest cost is for open SB cases $(12,103.00 €)$. In short, it is important to note that the direct and indirect cost components varied significantly between the four categories. For example, there is a difference in the cost of treatments between the walking and nonwalking categories. Similarly, the cost component for medical examinations differs between the walking and nonwalking and walking with complex orthoses (doubling the cost for nonwalking patients) groups. The cost per year was also higher for the patients in the $0-4$-year age range $(13,882.00 €)$ (Table 6 and Figure 4).

\section{Discussion}

No significant studies on the economic impact of SB in Italy had been carried out up to now, due to the difficulty in collecting data and developing and promoting studies for identifying the dynamics of the COI trends based on the evolution of the epidemiological situation and on incidence and lifetime cost data. This resulted in difficulties in proposing optimal health care policies.

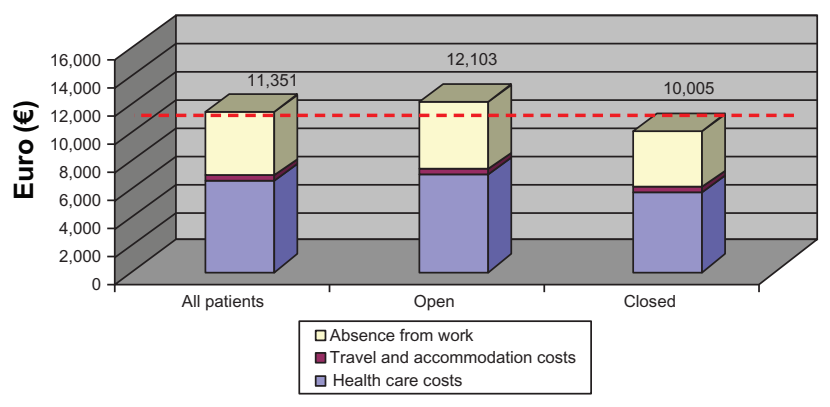

Figure 3 Anatomical type ratio of spina bifida: direct and indirect costs per year. 
Table 6 Direct and indirect costs per patient based on distribution by age

\begin{tabular}{|c|c|c|c|c|c|c|}
\hline & \multicolumn{2}{|l|}{$0-4$ years } & \multicolumn{2}{|l|}{$5-17$ years } & \multicolumn{2}{|l|}{$18+$ years } \\
\hline & Euros/year & $\%$ & Euros/year & $\%$ & Euros/year & $\%$ \\
\hline Medical examinations & $€ 549$ & $4.0 \%$ & $€ 676$ & $6.1 \%$ & $€ 493$ & $4.7 \%$ \\
\hline Emergency room & $€ 62$ & $0.4 \%$ & $€ 15$ & $0.1 \%$ & $€ 9$ & $0.1 \%$ \\
\hline Hospitalizations & $€ 2134$ & $15.4 \%$ & $€ 390$ & $3.5 \%$ & $€ 1047$ & $10.0 \%$ \\
\hline Diagnostic and laboratory tests & $€ 293$ & $2.1 \%$ & $€ 474$ & $4.3 \%$ & $€|3|$ & $1.3 \%$ \\
\hline Drug treatments & $€ 255$ & $1.8 \%$ & $€ 357$ & $3.2 \%$ & $€ 322$ & $3.1 \%$ \\
\hline Other treatments & $€ 85$ & $0.6 \%$ & $€ 49$ & $0.4 \%$ & $€ 69$ & $0.7 \%$ \\
\hline Assistive devices & $€ 5229$ & $37.7 \%$ & $€ 3916$ & $35.3 \%$ & $€ 4415$ & $42.2 \%$ \\
\hline Direct health care & $€ 8606$ & $62.0 \%$ & $€ 5877$ & $52.9 \%$ & $€ 6487$ & $61.9 \%$ \\
\hline Transportation & $€ 165$ & $1.2 \%$ & $€ 165$ & $1.5 \%$ & $€ 165$ & $1.6 \%$ \\
\hline Overnight stay & $€ 130$ & $0.9 \%$ & $€ 130$ & $1.2 \%$ & $€ 130$ & $1.2 \%$ \\
\hline Travel and accommodation costs & $€ 295$ & $2.1 \%$ & $€ 295$ & $2.7 \%$ & $€ 295$ & $2.8 \%$ \\
\hline $\begin{array}{l}\text { Absence from work } \\
\text { (including accompanying persons) }\end{array}$ & $€ 4981$ & $35.9 \%$ & $€ 4936$ & $44.4 \%$ & $€ 3692$ & $35.3 \%$ \\
\hline Total & $€ 13,882$ & $100.0 \%$ & $€ \mathrm{II}, \mathrm{I} 07$ & $100.0 \%$ & $€ 10,473$ & $100.0 \%$ \\
\hline
\end{tabular}

Data from this study indicate that the mean total cost per year for a patient with SB was 11,351.00 €. By using data provided by the Italian Institute of Health, ${ }^{1}$ we can estimate the total annual social cost to be about 60 million Euros per year. The priority problems of current health care systems are: a shortage of available resources to meet general growing health demands; providing comparison tools; developing health care projects and technologies according to criteria of efficacy and convenience; and identifying a scale of priorities to guide the use of public resources. Economic analysis applied to health care activities aims to highlight the most efficient use of the available resources, rather than to reduce expenditure. Economic analysis shows the importance of using suitable tools both for comparing data on the use of medications and health care technologies, and for helping doctors and health care professionals to optimize the resources at their disposal. ${ }^{18,19,24}$

The data emerging from this study highlight the need to obtain constant and thorough clinical and economic

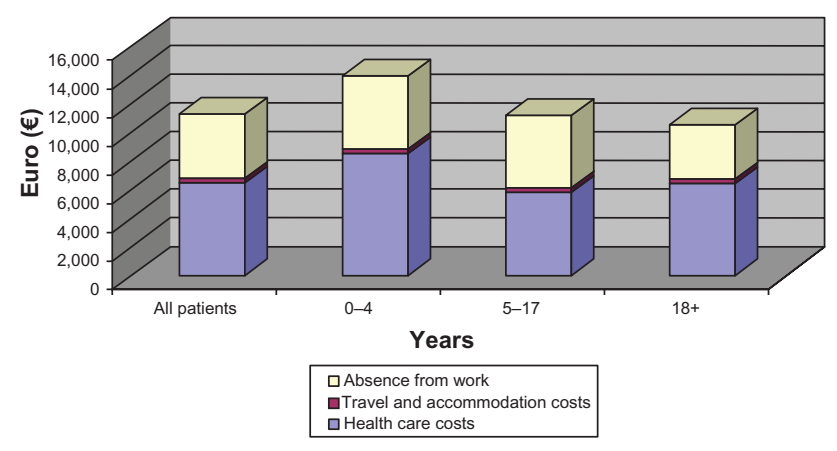

Figure 4 Direct and indirect costs per patient based on distribution by age. information on the number and severity of SB cases. Investments must be made into outcomes research to make these tools a constant reference point for decision making by physicians and people in charge of developing health care policies. ${ }^{27}$ Despite neurological repair surgery, spinal cord damage paralyzes the lower limbs and sphincters, SB is a complex and permanent disability that requires constant integrated multidisciplinary care. ${ }^{28} \mathrm{SB}$ patients and their families sustain considerable expenses that, according to the data that transpired, can be significant throughout the life of a subject with this kind of malformation. ${ }^{14-16}$ In many sectors, prevention activities in Italy appear to be inadequate compared to other cost components, since preference is given to programs that can generate the most immediate possible benefits, in order to produce social consensus around those promoting them. ${ }^{29}$

In any case, as was highlighted in the communication campaign by the patients' Spida Bifida (Associazione Spina Bifida Italia and Walter Vinci Onlus), it is important to consider the evaluation of the quality of life in SB patients and the extent of the commitment of SB patients to achieve greater independence. In this sense, a crucial role is played by information on health and the health care system, and by investments into outcomes research to make these tools a constant reference point for decision making by physicians and people in charge for developing health care policies.

\section{Acknowledgments}

The study was financially supported by Walter Vinci Onlus, Milan, Italy. 


\section{Disclosure}

The authors report no conflicts of interest in this work.

\section{References}

1. Istituto Superiore di Sanità. [National register of rare diseases: congenital malformation and folic acid] Registro Nazionale Malattie Rare: malformazioni congenite e acido folico [webpage on the Internet]. Pierini A, Bianchi F, Salerno P, Taruscio D, editors. Rome Italy, Istituto Superiore di Sanità; 2006. Available from: http://www.iss.it/publ/rapp/ cont.php?id=2012\&tipo $=5 \&$ lang $=1 \& c c s s=001$. Accessed December 10 , 2012. Italian.

2. Kinsman SL, Doehring MC. The cost of preventable conditions in adults with spina bifida. Eur J Pediatr Surg. 1996;6 Suppl 1:17-20.

3. Boyd PA, Devigan C, Khoshnood B, Loane M, Garne E, Dolk H; for EUROCAT Working Group. Survey of prenatal screening policies in Europe for structural malformations and chromosome anomalies, and their impact on detection and termination rates for neural tube defects and Down's syndrome. BJOG. 2008;115(6):689-696.

4. Calzolari E, Bianchi F, Dolk H, Stone D, Milan M. Are omphalocele and neural tube defects related congenital anomalies?: Data from 21 registries in Europe (EUROCAT). Am J Med Genet. 1997;72(1):79-84.

5. Bianca S, Bianca M, Bonaffini F, Ettore G. The role of maternal reproductive history in the aetiology of neural tube defects. Med Hypotheses. 2002;58(2):113-114.

6. De Marco P, Merello E, Calevo MG, et al. Maternal periconceptional factors affect the risk of spina bifida-affected pregnancies: an Italian case-control study. Childs Nerv Syst. 2011;27(7):1073-1081.

7. Rosano A, Botto LD, Botting B, Mastroiacovo P. Infant mortality and congenital anomalies from 1950 to 1994: an international perspective. J Epidemiol Community Health. 2000;54(9):660-666.

8. Källén K, Castilla EE, Robert E, Mastroiacovo P, Källén B. OEIS complex - a population study. Am J Med Genet. 2000;92(1):62-68.

9. Waitzman NJ, Romano PS, Scheffler RM. Estimates of the economic costs of birth defects. Inquiry. 1994;31(2):188-205.

10. Tilford JM, Grosse SD, Goodman AC, Li K. Labor market productivity costs for caregivers of children with spina bifida: a population-based analysis. Med Decis Making. 2009;29(1):23-32.

11. Centers for Disease Control and Prevention (CDC). Economic costs of birth defects and cerebral palsy - United States, 1992. MMWR Morb Mortal Wkly Rep. 1995;44(37):694-699.

12. Postma MJ, Londeman J, Veenstra M, de Walle HE, de Jong-van den Berg LT. Cost-effectiveness of periconceptional supplementation of folic acid. Pharm World Sci. 2002;24(1):8-11.

13. Zipitis CS, Paschalides C. Caring for a child with spina bifida: understanding the child and carer. J Child Health Care. 2003;7(2):101-112.

14. Macias MM, Saylor CF, Rowe BP, Bell NL. Age-related parenting stress differences in mothers of children with spina bifida. Psychol Rep. 2003;93(3 Pt 2):1223-1232.
15. Stewart MJ, Ritchie JA, McGrath P, Thompson D, Bruce B. Mothers of children with chronic conditions: supportive and stressful interactions with partners and professionals regarding caregiving burdens. Can J Nurs Res. 1994;26(4):61-82.

16. Wallander JL, Venters TL. Perceived role restriction and adjustment of mothers of children with chronic physical disability. J Pediatr Psychol. 1995;20(5):619-632.

17. Ament A, Evers S. Costs of illness studies in health care: a comparison of two cases. Health Policy. 1993;26(1):29-42.

18. Drummond M. Cost-of-illness studies: a major headache? Pharmacoeconomics. 1992;2(1):1-4.

19. Koopmanschap MA. Cost-of-illness studies. Useful for health policy? Pharmacoeconomics. 1998;14(2):143-148.

20. Italian Health Economics Association. Associazione Italiana di Economia Sanitaria - AIES, Proposta di linee guida per la valutazione economica degli interventi sanitari in Italia. [Italian guidelines proposal on how to conduct economic evaluation studies of health programs]. Pharmacoeconomics Italian Research Articles. 2009;11:83-93. Italian.

21. Health Ministry, DRG Tariff - TUC Tariffa Unica Convenzionale, Conferenza delle Regioni e delle Province Autonome, compensazione interregionale della mobilità sanitaria Testo Unico, Versione in vigore per le attività dell'anno 2010, Rome, May 5, 2011. Italian.

22. Health Ministry, "2010 National Healthcare Range of Fees" Nomenclatore delle Prestazioni di assistenza specialistica ambulatoriale, Ministero della Salute, 2011. Italian.

23. AIFA Italian Medicines Agency - Agenzia Italiana del Farmaco. Liste di Trasparenza [webpage on the Internet]. Available from: http:// www.agenziafarmaco.gov.it/it/content/liste-di-trasparenza-15042013. Accessed December 15, 2012. Italian.

24. Drummond MF, Sculpher MJ, Torrance GW, O'Brien BJ, Stoddart GL. Methods for the Economic Evaluation of Health Care Programmes, 3rd ed. New York, NY: Oxford University Press; 2006.

25. Bank of Italy. Banca D'Italia. La ricchezza delle famiglie italiane [Survey on Household Income and Wealth] - anno 2011, n. 65 - 2011 14-12-2011, Rome. [webpage on the Internet]. 2011. Available from: http://www.bancaditalia.it/statistiche/stat_mon_cred_fin. Accessed December 15, 2012. Italian.

26. ISTAT, Istituto Nazionale di Statistica. [National Institute of Statistic]. Available from: http://seriestoriche.istat.it/index.php?id=7\&user_100ind_ pi1[id_pagina] $=70 \& \mathrm{cHash}=468 \mathrm{e} 508 \mathrm{f} 3 \mathrm{~b} 1982 \mathrm{a} 1 \mathrm{c} 919 \mathrm{~b} 740 \mathrm{~b} 8 \mathrm{f} 13 \mathrm{~d} 66$. Accessed October 10, 2012. Italian.

27. Busby A, Abramsky L, Dolk H, et al. Preventing neural tube defects in Europe: a missed opportunity. Reprod Toxicol. 2005;20(3):393-402.

28. Wiegner S, Donders J. Predictors of parental distress after congenital disabilities. J Dev Behav Pediatr. 2000;21(4):271-277.

29. Colombo GL, Serra G, Morlotti L, Fara GM. The role of economic evaluation for the implementation of vaccination strategies. Ann Ig. 2005;17(6):479-490. Italian.
ClinicoEconomics and Outcomes Research

\section{Publish your work in this journal}

ClinicoEconomics \& Outcomes Research is an international, peerreviewed open-access journal focusing on Health Technology Assessment, Pharmacoeconomics and Outcomes Research in the areas of diagnosis, medical devices, and clinical, surgical and pharmacological intervention. The economic impact of health policy and health systems

\section{Dovepress}

organization also constitute important areas of coverage. The manuscript management system is completely online and includes a very quick and fair peer-review system, which is all easy to use. Visit http://www.dovepress.com/testimonials.php to read real quotes from published authors. 